(1)

CrossMark

\title{
It needs more than just eosinophils to cause emphysema in COPD
}

\author{
Florence Schleich and Renaud Louis \\ Affiliation: Respiratory Medicine, GIGA I3, CHU Sart-Tilman B35, Liege, Belgium.
}

Correspondence: Florence Schleich, CHU Sart-Tilman, Pulmonology, Sart-Tilman B35, B-4000 Liège, Belgium. E-mail: fschleichםchu.ulg.ac.be

@ERSpublications

It is of utmost importance to obtain smoking cessation in COPD patients exhibiting eosinophilic inflammation http://bit.ly/2VkkxQv

Cite this article as: Schleich F, Louis R. It needs more than just eosinophils to cause emphysema in COPD. Eur Respir J 2019; 53: 1900332 [https://doi.org/10.1183/13993003.00332-2019].

Asthma and chronic obstructive pulmonary disease (COPD) are chronic inflammatory diseases of the airways.

The role of inflammation and eosinophilia in lung function decline has been highlighted with high eosinophil sputum numbers [1], high variability in sputum eosinophils [2], and higher blood eosinophil numbers [3] linked to accelerated rate of lung function decline in asthma. Moreover asthma, which is known to be frequently associated with airway and blood eosinophilia [4], is a major risk factor for the development of COPD [5]. Lung function decline also occurs more frequently in COPD patients exhibiting increased eosinophilic inflammation [6]. One third of COPD patients indeed have airway eosinophilic inflammation $[7,8]$. Accelerated lung function decline is not the only feature of COPD.

Most COPD patients also exhibit emphysema, which implies lung tissue destruction. In COPD, macrophages and neutrophils not only mediate airway remodelling but also destruction after exposure to pollutants [9, 10]. In the current issue of the European Respiratory Journal, DoyLe et al. [11] found, in vitro, that eosinophil-derived interleukin (IL)-13 promoted alveolar macrophage-derived matrix metalloproteinase (MMP)-12 production, which has been shown to play a role in alveolar destruction [12]. They found that airspace enlargement is dependent on MMP-12, and that MMP-12 was increased in eosinophilic COPD patients exhibiting emphysema, while no differences were found between eosinophilic and non-eosinophilic subjects with asthma. In the study of CHAUdHuRI et al. [13], there was no significant association between asthma disease severity and sputum MMP-12 concentrations, but sputum MMP-12 in COPD patients was also directly associated with the extent of emphysema measured by computed tomography.

It is likely that eosinophils only play a role in the development of emphysema in patients inhaling pollutants. In this study, diffusing capacity of the lung for carbon dioxide was well preserved in nonsmokers with asthma, despite the higher frequency of eosinophilic inflammation in asthma [14, 15]. In asthma, the airspace enlargement is maybe more a sign of air trapping following airway remodelling than emphysema and destruction of the alveoli per se [16]. This suggests that additional mechanisms of eosinophilic inflammation are required to induce alveolar wall destruction. One can evoke oxidative stress induced following inhalation of pollutants or cigarette smoke and it has been shown that MMP-12 can also be produced by epithelial cells in response to cigarette smoke [17]. WoodrufF et al. [18] also 
suggested that MMP-12, which was elevated in smokers but not in asthma patients, might produce emphysema more readily in smokers with lower levels of antiproteinase activity.

Anti-IL-5 has very modest clinical benefit in COPD patients $[19,20]$ in terms of reduction of exacerbations. It is not excluded that long-term treatment with anti-IL-5 or anti-IL-13 in COPD could have an effect in preventing the development of emphysema. Perhaps the clinical message derived from the study reported by Doyle et al. [11] is that it is of utmost importance to obtain smoking cessation in these patients exhibiting eosinophilic inflammation.

Conflict of interest: None declared.

\section{References}

1 Broekema M, Volbeda F, Timens W, et al. Airway eosinophilia in remission and progression of asthma: accumulation with a fast decline of FEV1. Respir Med 2010; 104: 1254-1262.

2 Newby C, Agbetile J, Hargadon B, et al. Lung function decline and variable airway inflammatory pattern: longitudinal analysis of severe asthma. J Allergy Clin Immunol 2014; 134: 287-294.

3 Ulrik CS, Backer V, Dirksen A. A 10 year follow up of 180 adults with bronchial asthma: factors important for the decline in lung function. Thorax 1992; 47: 14-18.

4 Schleich FN, Chevremont A, Paulus V, et al. Importance of concomitant local and systemic eosinophilia in uncontrolled asthma. Eur Respir J 2014; 44: 97-108.

5 Silva GE, Sherrill DL, Guerra S, et al. Asthma as a risk factor for COPD in a longitudinal study. Chest 2004; 126: 59-65.

6 Hastie AT, Martinez FJ, Curtis JL, et al. Association of sputum and blood eosinophil concentrations with clinical measures of COPD severity: an analysis of the SPIROMICS cohort. Lancet Respir Med 2017; 5: 956-967.

7 Bafadhel M, Pavord ID, Russell REK. Eosinophils in COPD: just another biomarker? Lancet Respir Med 2017; 5: 747-759.

8 Schleich F, Corhay JL, Louis R. Blood eosinophil count to predict bronchial eosinophilic inflammation in COPD. Eur Respir J 2016; 47: 1562-1564.

9 Hautamaki RD, Kobayashi DK, Senior RM, et al. Requirement for macrophage elastase for cigarette smoke-induced emphysema in mice. Science 1997; 277: 2002-2004.

10 Sharafkhaneh A, Hanania NA, Kim V. Pathogenesis of emphysema: from the bench to the bedside. Proc Am Thorac Soc 2008; 5: 475-477.

11 Doyle AD, Mukherjee M, LeSuer WE, et al. Eosinophil-derived IL-13 promotes emphysema. Eur Respir J 2019; 53: 1801291.

12 Zheng $\mathrm{T}$, Zhu Z, Wang Z, et al. Inducible targeting of IL-13 to the adult lung causes matrix metalloproteinaseand cathepsin-dependent emphysema. J Clin Invest 2000; 106: 1081-1093.

13 Chaudhuri R, McSharry C, Brady J, et al. Sputum matrix metalloproteinase-12 in patients with chronic obstructive pulmonary disease and asthma: relationship to disease severity. J Allergy Clin Immunol 2012; 129: 655-663.

14 Schleich F, Brusselle G, Louis R, et al. Heterogeneity of phenotypes in severe asthmatics. The Belgian Severe Asthma Registry (BSAR). Respir Med 2014; 108: 1723-1732.

15 Schleich FN, Manise M, Sele J, et al. Distribution of sputum cellular phenotype in a large asthma cohort: predicting factors for eosinophilic vs neutrophilic inflammation. BMC Pulm Med 2013; 13: 11.

16 Gelb AF, Yamamoto A, Verbeken EK, et al. Further studies of unsuspected emphysema in nonsmoking patients with asthma with persistent expiratory airflow obstruction. Chest 2018; 153: 618-629.

17 Lavigne MC, Eppihimer MJ. Cigarette smoke condensate induces MMP-12 gene expression in airway-like epithelia. Biochem Biophys Res Commun 2005; 330: 194-203.

18 Woodruff PG, Koth LL, Yang YH, et al. A distinctive alveolar macrophage activation state induced by cigarette smoking. Am J Respir Crit Care Med 2005; 172: 1383-1392.

19 Brightling CE, Bleecker ER, Panettieri RA, Jr. et al. Benralizumab for chronic obstructive pulmonary disease and sputum eosinophilia: a randomised, double-blind, placebo-controlled, phase 2a study. Lancet Respir Med 2014; 2: 891-901.

20 Pavord ID, Chanez P, Criner GJ, et al. Mepolizumab for eosinophilic chronic obstructive pulmonary disease. N Engl J Med 2017; 377: 1613-1629. 